\title{
CERVICECTOMY WITH UTEROVAGINAL ANASTOMOSIS IN THE RHESUS MONKEY: A NEW SURGICAL MODEL FOR REPRODUCTIVE STUDIES*
}

\author{
E. AZAR $\dagger$ AND S. T. SHAW, JR \\ Departments of Obstetrics and Gynecology and Pathology, \\ University of Southern California School of Medicine, \\ 1321 North Mission Road, Los Angeles, California 90031, U.S.A.
}

(Received 13th August 1974)

\begin{abstract}
Summary. Cervicectomy with uterovaginal anastomosis in the rhesus monkey allows easy and non-traumatic access to the uterine cavity through the vagina for such purposes as biopsy, flushing, aspiration of fluid, and placement of IUDs. Endometrial and tissue samples cannot be contaminated by cervical mucus. The surgical procedure and results on eleven animals are described. Neither uterine nor ovarian function appeared to be significantly altered. The surgical model seems well suited to long-term studies on IUDs.
\end{abstract}

\section{INTRODUGTION}

As a means of conveniently entering the uterine cavity of the rhesus monkey, by-passing the very tortuous and narrow endocervical canal of this species, uterocutaneous abdominal fistulae have been employed (Van Wagenen \& Morse, 1940; Good \& Moyer, 1966; Shaw, Moyer, Poon \& Nogueira, 1972). Such fistulae were surgically constructed between the anterior abdominal surface and the fundus of the uterine cavity. In order to prevent contamination of uterine cavity samples with cervical mucus, a uterocutaneous abdominal fistula has been employed in baboons in which the uterus is severed from its cervix and the cervical end of the uterine cavity is surgically anastomosed to the abdominal skin surface (Breed, Fraser, Eckstein \& Peplow, 1972). For many studies of reproductive processes in non-human primates, these surgical models have obvious advantages, but also certain disadvantages. For this reason, another model which avoided the cervical canal for access into the uterine cavity was developed in the rhesus monkey. This procedure employed removal of the cervix with uterovaginal anastomosis.

\section{MATERIALS AND METHODS}

Eleven rhesus monkeys ranging between 5 and 7 years in estimated age were subjected to the surgical procedure. All were observed for menstrual cyclicity and their menstrual blood loss (MBL) was quantified for several months

* Reprint requests to Dr S. T. Shaw, Jr.

$\uparrow$ Present address: P.O. Box 6360, Amman, Jordan. 
before and after surgery by the method described by Poon, Moyer, Forino \& Shaw (1973). Because of prolonged periods of amenorrhoea before surgery, cycles were induced artificially in five monkeys by daily injections of oestradiol with or without progesterone as previously detailed (Shaw et al., 1972).

\section{Procedure}

The animals were anaesthetized with an intramuscular injection of phencyclidine hydrochloride supplemented with intraperitoneal pentobarbital when necessary. The vagina was swabbed with benzalkonium chloride $1: 1000$ and the urinary bladder was catheterized with a No. 8 French rubber catheter. In the supine position, the lower abdomen was shaved, scrubbed, and draped. The abdominal cavity was entered by a mid-line, vertical, infraumbilical incision through the skin, subcutaneous tissue, anterior rectus sheath, and peritoneum in layers. The bowel and omentum were gently packed

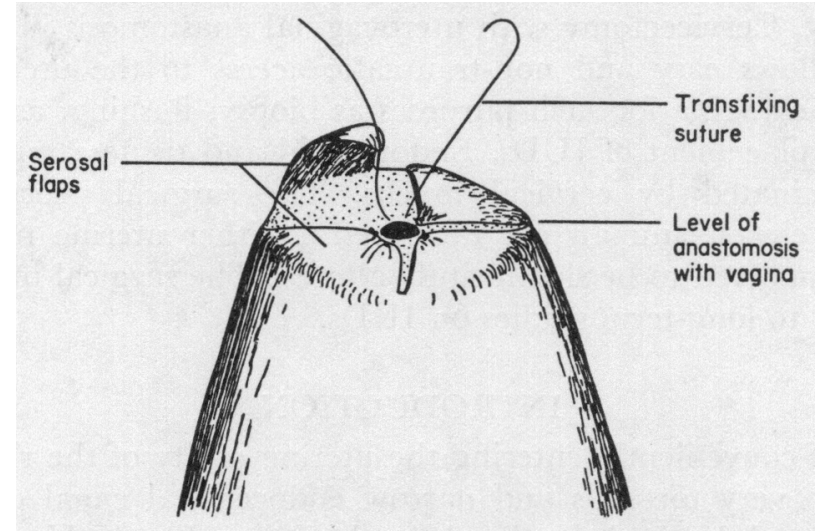

TexT-fic. 1. A diagramatic representation of the lower portion of a rhesus monkey uterus with the cervix amputated, showing three uterine serosal flaps transfixed near the internal cervical os and one being sutured to the cut surface of the corpus uteri.

out of the way, and suprapubic and self-retaining abdominal retractors were applied. The uterus was held under tension by grasping the round ligaments with haemostats. A $1-\mathrm{cm}$ hole was made with a haemostat in each broad ligament close to the uterus but above the uterine vessels. The reflexion of bladder peritoneum onto the uterus was then cut and the incision was carried laterally to the holes in the broad ligaments. Bladder peritoneum could then be removed from the anterior cervix uteri by blunt dissection. The peritoneum was cut posteriorly starting from one hole in the broad ligament and carrying the incision over the origin of the uterosacral ligaments to the opposite side. The posterior peritoneum overlying the rectum was then reflected down and separated from the cervix. After carefully dissecting the areolar tissue surrounding the uterine artery and vein on each side, the vessels were double clamped with small straight Kocher haemostats, divided and ligated with 2-0 chromic catgut. The stump caught by the second clamp on each side was similarly ligated to prevent backflow bleeding. The thin pubocervical fascia was next incised transversely and bluntly dissected. The cervical branches of the uterine vessels and the cardinal ligaments were clamped, cut, and ligated close to the body 
of the cervix. The anterior vaginal vault was incised and the incision was extended around the cervix, detaching it from the vagina. The distal end of the uterus was severed with a blade, starting $1 \mathrm{~cm}$ from the exocervix and cutting away the cervix in slices until the internal os was exposed. The latter was dilated with a vascular probe to $3 \mathrm{~mm}$ diameter to enable the insertion of an IUD. Four serosal flaps were developed at the transected end, folded over the cut surface, and secured by $4-0$ chromic catgut sutures joining the tip

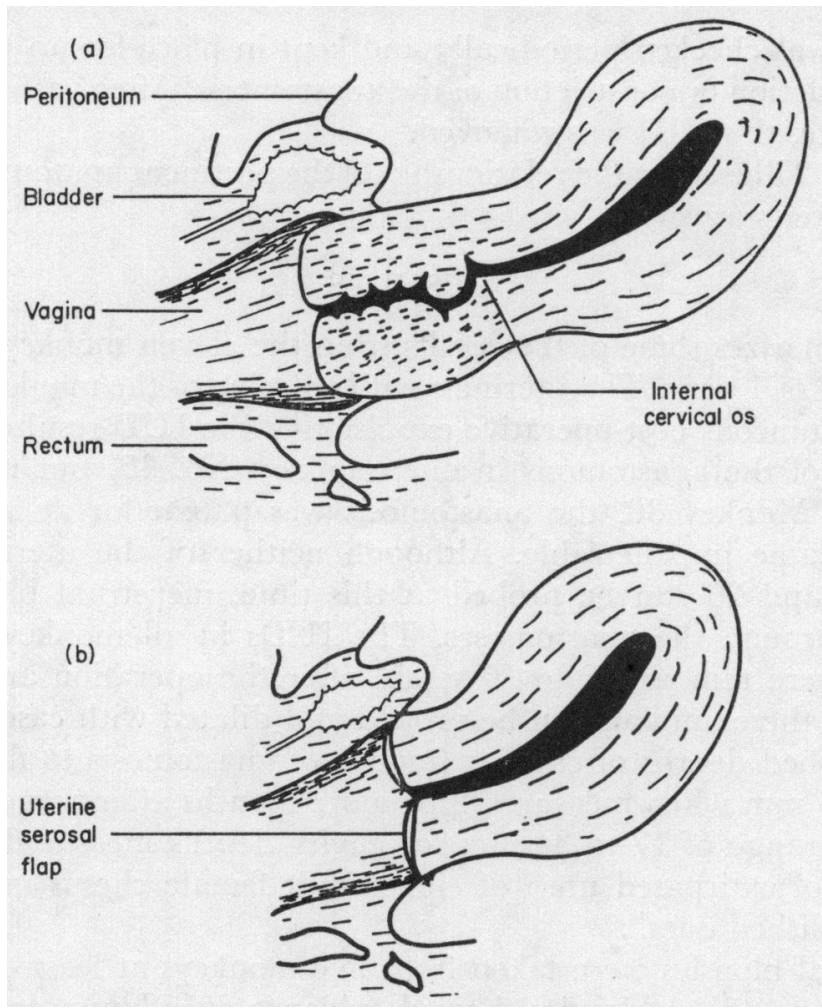

Text-Fig. 2. A diagrammatic lateral view of a rhesus monkey uterus. (a) Before operation. Note the narrow tortuous cervical canal and bulky anterior colliculus distal to the internal cervical os. (b) After anastomosis of the corpus uteri to the vagina following amputation of the cervix uteri at the internal os.

of the serosa to the perimeter of the dilated opening into the uterus (see Text-fig. 1) to prevent stricture of the vaginal apex after anastomosis. A Tatum-T IUD with the horizontal arms cut down to $0.8 \mathrm{~cm}$ each and permanently shaped into a $\mathrm{Y}$ configuration was inserted with the $\mathrm{V}$-shaped arms closed. After insertion, the long vertical limb extended through the internal os. The lower part of the uterus and vaginal cuff were anastomosed by means of three pairs of interrupted 2-0 silk sutures that were kept loose until all were placed, after which they were tied and cut. The anterior surface of the body of the uterus was covered with peritoneum, joining the anterior leaf of the broad ligament and bladder peritoneum with a continuous 3-0 chromic catgut suture. A similar suture was placed posteriorly, joining the posterior leaf of the broad ligament and posterior peritoneum. Before closing the 
abdomen, the uterus was palpated and was always seen to blanch on pressure and flush promptly thereafter, indicating the presence of a good blood supply. During surgery, the ovarian vessels were always easy to identify. The ovarian veins were particularly prominent and generally became progressively more dilated during the surgical procedure. The peritoneum was closed with a continuous 3-0 chromic catgut suture, the anterior rectus fascia with interrupted 2-0 chromic catgut and the skin with interrupted 2-0 braided steel sutures.

The IUD was checked periodically and kept in place for up to 10 weeks to prevent obstruction or constriction of the anastomosis. After healing was judged to be complete, the IUD was removed.

Text-figure 2 illustrates the relationship of the pertinent anatomical structures before and after surgery.

\section{RESULTS}

Table 1 summarizes some of the results from the eleven monkeys operated on over the span of 1 year. The uterine cavities of nine of the monkeys can still be probed. Spontaneous post-operative expulsion of the IUD resulted in blockage or distortion of the anastomosis in one monkey (No. 35) but not in another (No. 32). In Monkey 36, the anastomosis was patent for at least 5 months but later became impenetrable. Although neither of the uterine cavities of Monkeys 35 and 36 can be probed at this time, menstrual blood is readily discharged through the anastomoses. The IUDs in all monkeys, except Nos 32 and 35, were removed 6 to 10 weeks after the operation and the uterine cavities of all these animals can be probed and dilated with ease and minimal bleeding. Probed depths of cavities (mouth of anastomosis to fundus) ranged from 23 to $35 \mathrm{~mm}$ when measured 2 or more months after surgery. This compares with a range of 17 to $34 \mathrm{~mm}$ for cavity depths measured from silicone rubber casts of extirpated uteri of eight adult female rhesus monkeys (S. T. Shaw, unpublished data).

Endometrial biopsies were taken from five monkeys at least 4 months after operation. None of the biopsies showed evidence of inflammatory or atrophic

Table 1. Results of cervicectomy followed by the uterovaginal anastomosis in eleven rhesus monkeys

\begin{tabular}{c|c|c|c}
\hline $\begin{array}{c}\text { Monkey } \\
\text { no. }\end{array}$ & $\begin{array}{c}\text { Months } \\
\text { after } \\
\text { surgery }\end{array}$ & $\begin{array}{c}\text { Patency } \\
\text { of } \\
\text { anastomosis }\end{array}$ & $\begin{array}{c}\text { Depth of uterine } \\
\text { cavity probed }(\mathrm{mm})\end{array}$ \\
\hline 39 & 1 & + & - \\
38 & 2 & + & 23 \\
41 & 3 & + & 32 \\
40 & 4 & + & 30 \\
34 & 4 & + & 35 \\
30 & 5 & + & 28 \\
32 & 10 & + & 31 \\
36 & 11 & + & 23 \\
31 & 11 & - & 23 \\
42 & 11 & + \\
35 & 12 & & - \\
\hline
\end{tabular}


changes. Glandular and stromal elements appeared normal for the time of cycle in each case.

The cycle length in monkeys spontaneously menstruating both before and after surgery were compared. For twenty-one cycles before and twelve following surgery, mean and standard deviations were $31.05 \pm 6.31$ and $28.83 \pm 6.73$, respectively. Variances and means were not significantly different by $\mathrm{F}$ and two-tailed $t$ tests $(\mathrm{F}=0.881, P>0.05 ; t=0.947, P>0.2)$.

A comparison of MBL before and after surgery was made for those animals whose cycles were not under the influence of injected oestradiol and progesterone. The mean blood loss per period was $1.68 \mathrm{ml}$ before surgery (52 periods) versus $1.51 \mathrm{ml}$ following surgery (22 periods). This difference was not statistically significant by either the Mann-Whitney $\mathrm{U}$ test $(P=0.174)$ or the $t$ test $(t=$ $0 \cdot 726, P>0 \cdot 4)$.

To determine if an IUD could still be inserted and retained after removal of the first device, a second IUD was placed 2 months later through the anastomosis in Monkeys 31 and 42. This was accomplished with ease through a commercial inserter (Cu-7 inserter, G. D. Searle and Co., Box 5110, Chicago, Illinois 60680) and the IUDs remained in place for 6 weeks until they were removed.

\section{DISCUSSION}

The fundal uterocutaneous fistula (Van Wagenen \& Morse, 1940; Good \& Moyer, 1966) has been extensively employed in this laboratory for studies of uterine physiology and uterine response to foreign bodies (Shaw, Cihak \& Moyer, 1970; Shaw et al., 1972; Poon et al., 1973; Shaw, Jimenez, Moyer \& Cihak, 1973; Shaw, Poon \& Moyer, 1974; Poon, Shaw \& Moyer, 1974). This model continues to be useful for such studies, but is associated with inherent problems. In many animals, the fistula does not remain patent without regular probing and in some, the fistula heals so completely in a short period of time that a further operation is necessary. The fistula also provides a new route, in addition to the cervical canal, through which an IUD may be expelled. Moreover, any device placed in the uterine cavity which has an appendage extending through the fistula to the abdominal surface will be removed by the animal. This is particularly disadvantageous in the case of experiments involving IUDs for which appendages such as a nylon suture are helpful in removing the device. Without such means of removal, it is sometimes necessary to remove devices surgically from deep inside the uterine cavity. Also, an attached suture visible outside the uterus provides a simple means of checking to ensure that an IUD is in place. Although patency of the uterovaginal anastomosis has not been proven beyond 11 months, early results indicate that the uterovaginal anastomosis model is more successful than the uterocutaneous fistula model in all the respects discussed above. A modified plastic $T$ device is easily inserted and is well retained. An appendage of the device may be made to extend into the vagina where it can be observed to check retention or grasped for easy removal of the device.

Probing and widening of the fistula model before instrumentation of the cavity often produces considerable bleeding so that uterine fluid samples, 
including flushings, become contaminated with blood. By contrast, the uterovaginal channel may be dilated gently with little or no bleeding, since the relatively expansile, muscular lower portion of the uterine body surrounds the orifice of the cavity in this model.

In the animal with a uterovaginal anastomosis, as with the two uterocutaneous fistula models, samples may be removed from the uterine cavity or its lining without contamination by cervical mucus. All three models, however, may be unsuitable for studies in late pregnancy.

In the baboon abdominal fistula model (Breed et al., 1972), as in the case described here, the uterine blood supply from the iliac arteries is destroyed. In both models, however, there is no evidence for altered structure or function of either the ovaries or the body of the uterus. Breed et al. (1972) described normal cyclicity, sexual skin, endometrial histology, and progesterone levels following their surgical procedure. From our results on cyclicity, menstrual blood volume, endometrial biopsies, and assessment of uterine size, we also find no change from the preoperative state. These findings apparently result primarily from the rich blood supply from the ovarian arteries to the uterus in primates. Great care was taken to maintain the anatomical integrity of the ovarian vasculature in our procedure in order to provide sufficient blood flow to the remaining uterus. Several cases have been reported in which women conceived and carried normal, full-term offspring to normal birth following ligation of both uterine arteries (Keith, 1972; Mengert, Burchell, Blumstein \& Daskal, 1969).

\section{AGKNOWLEDGMENTS}

This work was supported by a grant from the Ford Foundation. The authors are grateful for the excellent technical assistance of $\mathrm{Mr} \mathrm{R}$. V. Forino.

\section{REFERENCES}

Breed, W. G., Fraser, A., Eckstein, P. \& Peplow, P. V. (1972) Physiological studies on the baboon uterus by means of utero-cutaneous fistula. In Medical Primatology, pt 1, pp. 206-215. Eds. E. I. Goldsmith and J. Moor-Jankowski. Karger, Basel.

Good, R. G. \& Moyer, D. L. (1966) Technique of serial endometrial biopsy in the monkey through a utero-cutaneous fistula. 7. Reprod. Fert. 12, 573-574.

KerTH, L. (1972) Surgical management of intractable pelvic hemorrhage. In Davis' Gynecology and Obstetrics, Vol. III, part II, chap. 49, pp. 1-8. Ed.J.J. Rovinsky. Harper \& Row, Hagerstown, Md.

Mengert, W. F., Burchell, R. C., Blumstein, R. W. \& Daskal, J. L. (1969) Pregnancy after bilateral ligation of the internal iliac and ovarian arteries. Obstet. Gynec., N.Y. 34, 664-666.

Poon, G. H., Moyer, D. L., Forino, R. V. \& Shaw, S. T., JR (1973) Studies on menstrual blood loss in intact and experimental rhesus monkeys. F. med. Primat. 2, 353-363.

Poon, C. H., Shaw, S. T., JR \& Moyer, D. L. (1974) Technique for obtaining pure endometrial fluid from rhesus monkeys. F. Reprod. Fert. 36, 413-415.

Shaw, S. T., JR, GihaK, R. W. \& Mover, D. L. (1970) Fibrin proteolysis in the monkey uterine cavity: variations with and without IUD. Nature, Lond. 228, 1097-1098.

Shaw, S. T., Jr, Jimenez, J. M., Moyer, D. L. \& GrhaK, R. W. (1973) Relationship of endometrial plasminogen activator to fibrin proteolysis in the uterine cavity of rhesus monkeys. $A m$. 7 . Obstet. Gynec. 115, 983-985.

Shaw, S. T., JR, Moyer, D. L., Poon, C. H. \& Nogueira, T. P. W. (1972) Studies of menstrual physiology using the uterocutaneous fistula model of Macaca mulatta. In Medical Primatology, pt 1, pp. 317-324. Eds. E. I. Goldsmith and J. Moor-Jankowski. Karger, Basel.

Shaw, S. T., JR, Poon, G. H. \& Moyer, D. L. (1974) Uterine bleeding in the rhesus monkey in response to various designs of intrauterine devices. Fert. Steril. 25, 358-362.

Van Wagenen, G. \& Morse, A. H. (1940) Cyclic changes in the exteriorized uterus. Endocrinology, 27, 268-273. 